Sufiyanto dan Budi Prijo Sembodo : Rancangan Sistem Kendali Penerangan Pada Fixed Bridge Secara Otomatis Untuk Efisiensi Daya Listrik

\title{
RANCANGAN SISTEM KENDALI PENERANGAN PADA FIXED BRIDGE SECARA OTOMATIS UNTUK EFISIENSI DAYA LISTRIK
}

\author{
Sufiyanto $^{1)}$, dan Budi Prijo Sembodo ${ }^{2)}$ \\ ${ }^{1)}$ dan 2) Program Studi Teknik Elektro; Fakultas Teknologi Industri (FTI) \\ Universitas PGRI Adi Buana Surabaya \\ Email : $\underline{\text { Sufi.yanto@ymail.com }}$
}

\begin{abstract}
Abstrak
Penelitian ini untuk mencarikan solusi mengatasi masalah penerangan di lorong fixed bridge yang menyala selama dua puluh empat jam, walaupun ruangan tersebut tidak dipakai untuk aktifitas naik dan turunnya penumpang. Metode yang digunakan yaitu analisis Diskriptif dengan membuat suatu Rancangan sistem kendali penerangan yang bekerja secara otomatis dilorong fixed bridge. Cara kerja rancangan ini adalah dengan menggunakan dua buah sensor yaitu sensor cahaya yang bekerja pada kondisi gelap dan Photoelectric Sensor yang bekerja bila sinar infrared terhalang oleh penumpang pesawat udara. Photoelectric Sensor memberikan trigger tegangan 24 VDC ke Programmable Logic Controller sebagai pengendali dari rancangan sistem kendali penerangan, pemrograman pada PLC menggunakan bahasa Ladder Diagram untuk memudahkan teknisi Bandara melakukan setting ulang waktu penerangan menyala. Rancangan ini dapat dioperasikan secara manual dengan menggunakan sakelar yang dipasang pada sitiap panel fixed bridge bila terjadi kegagalan operasi dari sistem rancangan. Pemakaian daya listrik di lorong fixed bridge menjadi efektif dan efisien karena penerangan menyala pada saat ruangan tersebut terpakai. Rancangan ini menjadi solusi mengatasi masalah yang ada selama ini. Penulis berharap agar rancangan ini dapat dikembangkan pada waktu yang akan datang dan menjadi referensi di bandar udara lain yang mempunyai permasalahan yang sama.
\end{abstract}

Kata kunci : Fixed bridge, LDR, Photoelectric sensor, PLC.

\begin{abstract}
This research is to find solutions to overcome the problem of lighting in the hallways fixed bridge lit for twenty-four hours, though the room is not used for activity rising and falling passenger. The method used is the analysis descriptif by creating a lighting control system design that works automatically in the hallway of a fixed bridge. The workings of this design is to use two sensors are light sensors that work in dark conditions and Photoelectric Sensor works when infrared light is blocked by air passengers. Photoelectric Sensors provide the trigger voltage of 24 VDC to a Programmable Logic Controller as the controller of a lighting control system design, programming in Ladder Diagram PLC to use language to facilitate the service technician setting up the lighting time on. This design can be operated manually using a switch mounted on panel sitiap fixed bridge where the failure of the operation of the system design. Power consumption in the hallways fixed bridge to be effective and efficient because the illumination light when the room unused. The design is a solution to overcome the existing problems so far. The author hopes that this design can be developed in the future and become a reference in other airports which have similar problems.
\end{abstract}

Keywords: Fixed bridge, LDR, Photoelectric sensors, PLC. 


\section{PENDAHULUAN}

PT. (Persero) Angkasa Pura I yang merupakan Badan Usaha Milik Negara (BUMN) yang bergerak dalam bidang pengusahaan jasa kebandar-udaraan. Pada PP No. 5 Tahun 1992 PT.(Persero) Angkasa Pura I mempunyai tugas pokok sebagai berikut:

1. Peningkatan penyediaan, pengusahaan dan pengembangan jasa Bandar udara.

2. Peningkatkan perencanaan, pengembangan, dan pemeliharaan Bandar udara

Fasilitas pendukung diterminal salah satunya adalah Garbarata (Passenger terminal building) yang merupakan jembatan yang berdiding dan beratap yang menghubungkan ruang tunggu penumpang dengan pintu pesawat terbang untuk memudahkan penumpang masuk kedalam dan keluar pesawat. Keuntungan memakai Garbarata adalah penumpang dapat terlindungi dari cuaca yang panas dan hujan. Pada terminal I (satu) memiliki 14 (empat belas unit) Garbarata, dimana semua Garbarata yang ada tidak bisa langsung dihubungkan dengan ruang tunggu karena disisi Air Side terdapat jalan yang dipakai untuk kendaraan yang beroperasi di area Air Side.

Untuk itu dipasang jembatan penghubung (fixed bridge) antara Garbarata dengan ruang tunggu penumpang pesawat udara. Ada 11 (sebelas) buah jembatan penghubung di Bandar Udara.. Penerangan diarea ruang fixed bridge penyalaannya disetting mulai pukul 00:00 s/d 24:00 wib ( dua puluh empat jam) karena area tersebut terhubung dengan ruangan lain seperti Toilet dan musholla, sehingga tidak memungkinkan penyalaan penerangan di area tersebut disetting tersendiri.

Untuk menghindari pemakaian daya listrik yang tidak efisien tersebut akibat dari pemakaian untuk penerangan dilorong fixed bridge yang menyala terus menerus selama dua puluh empat jam, maka perlu diadakannya suatu sistem kontrol yang mengatur kerja dari penerangan pada area tersebut tanpa mengurangi rasa aman dan nyaman bagi pengguna jasa penerbangan di Bandar Udara.

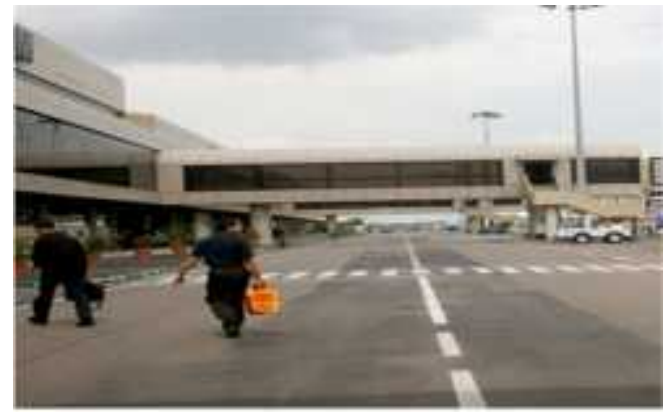

Gambar 1. Fixed Bridge

Tujuan perancangan sistem kendali penerangan pada lorong fixed bridge adalah untuk memberikan solusi atau jalan keluar terhadap sistem penerangan yang ada sekarang tanpa mengurangi rasa aman dan nyaman bagi pengguna jasa terminal Bandar Udara. Sedangkan manfaatnya adalah pemakaian daya listrik di lorong fixed bridge menjadi efektif dan efisien karena penerangan menyalah hanya pada saat fixed bridge di gunakan.

\section{METODE}

Penelitian ini adalah penelitian tindakan yang bertujuan untuk mengembangkan keterampilan baru atau cara pendekatan baru untuk memecahkan dengan penerapan langsung di dunia kerja. Metode pengumpulan data menggunakan metode observasi dengan melakukan pengamatan hasil pengujian shoftware yang disimulasikan dan uji perkomponen. Tahapan dalam penelitian meliputi blok diagram, perancangan perangkat keras dan perancangan perangkat lunak :

\section{Blok Diagram}

Perencanaan merupakan tahapan penting dalam pembuatan suatu tugas akhir. Perancangan ini meliputi spesifikasi komponen yang terdapat pada rangkaian perangkat keras dan dukungan perangkat lunak. Adapun tujuan dari perancangan alat ini adalah untuk menghasilkan alat yang sesuai dengan spesifikasi yang diharapkan, dengan memperhatikan segi-segi yang mendukung dalam merealisasikan alat tersebut dengan meminimalisir kesalahan-kesalahan yang mungkin terjadi.

Langkah awal dalam perancangan alat ini adalah membuat blok diagram dari rangkaian yang akan dibuat. Tujuannya adalah untuk mempermudah penganalisaan, yaitu hubungan antara komponen-komponen dalam satu blok ataupun blok lainnya agar dapat lebih mudah diketahui dengan jelas. Berikut ini adalah blok diagram dari rangkaian yang terdapat pada 
rancangan sistem kendali penerangan pada fixed bridge.

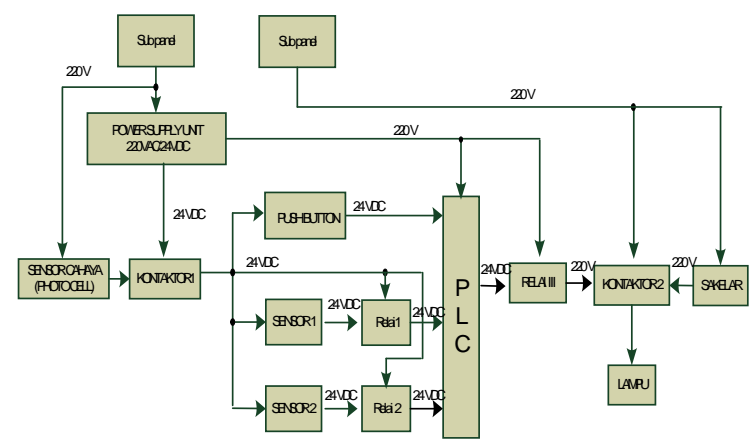

Gambar 2. Blok diagram rancangan

Dari gambar blok diagram diatas dapat dijelaskan sebagai berikut:

1. Tegangan 220VAC dari sub.panel 23 mengalir melalui MCB 10A ke panel kontrol rancangan sistem kendali meuju power supply, sensor cahaya (LDR), PLC dan kotaktor.

2. Dari power supply tegangan AC $220 \mathrm{~V}$ diturunkan dan disearahkan menjadi 24VDC. Tegangan 24VDC digunakan untuk mengerjakan photoelectric sensor, relai 24VDC dan tegangan kerja Programmable Logic Kontroller.

3. Tegangan 220VAC yang menuju sensor cahaya digunakan untuk tegangan kerja dari sensor dan yang menuju ke kontaktor II digunakan untuk tegangan kerja kontaktor.II.

4. Sensor Cahaya akan bekerja pada kuat cahaya 80 lux atau pada kisaran jam 17:30 wib, dan akan Off pada kuat cahaya 400 lux.atau pada kisaran jam 05:30 wib untuk menhidupkan dan mematikan kontaktor I. Kontak point kontaktor I mengalir tegangan 24VDC dari power supply. Tegangan 24VDC sebagai inputan photoelectric sensor 1 dan 2, push button dan kontak point relai 24VDC.

5. Apabila sinar infrared terpotong/terhalang oleh penumpang pesawat udara maka sensor tersebut akan mengerjakan relai 24VDC sehingga tegangan 24VDC yang ada dikontak point relai akan mengalir sebagai tegangan trigger ke PLC.

6. Setelah mendapat tegangan input/triger PLC akan bekerja sesuai dengan waktu setting PLC (3 menit), output dari PLC digunakan untuk menghidupkan relai 24VDC. Output dari relai 24 VDC akan digunakan untuk menghidupkan kontaktor II. Kerja dari kontaktor II akan menghidupkan 12 lampu penerangan diarea fixed bridge. Apabila sebelum habis waktu tetapi ada trigger lagi (penumpang memotong sinar infrared lagi) maka PLC akan menghitung kembali mulai dari 0 sampai 3 menit lagi.

7. Untuk tombol push button bila ditekan maka akan memberikan tegangan trigger 24 VDC ke PLC, setelah mendapatkan tegangan masukan PLC akan bekerja sesuai dengan waktu setting PLC yang dioperasikan dengan tombol (5 menit) kemudian output dari PLC akan menghidupkan relai 24VDC, output dari relai akan digunakan menghidupkan kontaktor II untuk menghidupkan lampu penerangan, Sumber tegangan untuk lampu penerangan menggunakan instalasi lama.

8. Sakelar tunggal digunakan apabila rancangan sistem kendali mengalami gagal operasi atau dalam perbaikan.

9. Langkah dari cara kerja ini berlaku untuk 11 fixed bridge yang ada di terminal 1 Bandar Udara Internasional Juanda Surabaya.

\section{a. Alat Dan Bahan Yang Digunakan}

Pada perancangan dan pembuatan sistem kendali penerangan pada fixed bridge secara otomatis untuk efisiensi daya listrik di bandar udara internasional juanda-Surabaya ini digunakan alat dan komponen sebagai berikut:

1. Power Supply

Sebagai pengubah dari tegangan AC ke DC yang bertujuan untuk mendapatkan tegangan DC sesuai dengan besaran tegangan yang dibutuhkan yaitu 24VDC. 24VDC digunakan untuk tegangan kerja sensor, relay dan Progammable Logic Controller.

2. Sensor cahaya digunakan untuk menghidupkan/memberikan tegangan 220V ke kontaktor 1.

3. Photoelectric Sensor

Digunakan sebagai pendeteksi sebuah obyek pada jarak tertentu dengan cara meletakan sensor transmitter dan receiver secara berhadapan yang bertujuan untuk mendapatkan logika 0 dan1 sebagai trigger ke PLC melalui relai $24 \mathrm{VDC}$.

4. Progammable Logic Controller

Sebagai alat kontrol yang dapat diprogram sehingga menghasilkan output yang diinginkani dengan cara memilih spesifikasi PLC berdasarkan tegangan 
Sufiyanto dan Budi Prijo Sembodo : Rancangan Sistem Kendali Penerangan Pada Fixed Bridge Secara Otomatis Untuk Efisiensi Daya Listrik

kerja PLC, jumlah I/O, tegangan masukan dan keluaran serta bahasa pemrogramannya sesuai dengan rancangan yang akan dibuat dengan tujuan untuk mendapatkan sistem rancangan yang diingikan.

5. Push Button dan Saklar tunggal

Push button sebagai trigger atau sinyal tegangan ke PLC dengan cara menekan tombol push button tujuannya untuk menjalan ke PLC dengan nilai waktu tertentu.

Saklar tunggal sebagai penghubung dan pemutus suatu rangkaian secara manual ke sebelas lampu bila terjadi kegagalan sistem kendali penerangan.

6. Relai 24VDC

Relai-I dan II 24VDC sebagai penghubung dan pemutus suatu rangkaian dari photoelectric sensor I dan II ke Programmable Logic Controller .

Relai-III 24VDC sebagai penghubung dan pemutus suatu rangkaian dari PLC ke kontaktor II.

7. Kontaktor

Kontaktor I sebagai penghubung dan pemutus suatu rangkaian dari PSU ke saklar trigger dan photoelectric sensor I dan II dengan cara On dan Off nya menyesuaikan kerja sensor cahaya. Sedangkan kontaktor II sebagai penghubung dan pemutus lampu penerangan.

\section{HASIL DAN PEMBAHASAN}

Pada bagian ini akan dijelaskan pengujian yang telah dilakukan yaitu pengujian Software dan hardware. Pengujian software salah satunya simulasi rancangan.

\section{a) Pengujian Software}

Salah satu keunggulan Zeliosoft adalah kemampuan untuk mensimulasikan diagram ladder yang telah dibuat apakah dapat berjalan sesuai dengan kondisi yang diharapkan atau tidak.

$\begin{array}{rrrr}\text { Pada } & \text { rancangan ini disimulasikan } \\ \text { tegangan } & \text { masukan }\end{array}$
diskrit/digital. Yaitu Z1 untuk Photoelektrik sensor 1, Z2 untuk Photoelektrik sensor 2 dan Z3 untuk Push button. Hasil dari kerja sensor 1,2 dan push button dapat kita lihat hasilnya pada keluaran Q1 yang disimbolkan berupa lampu pijar,

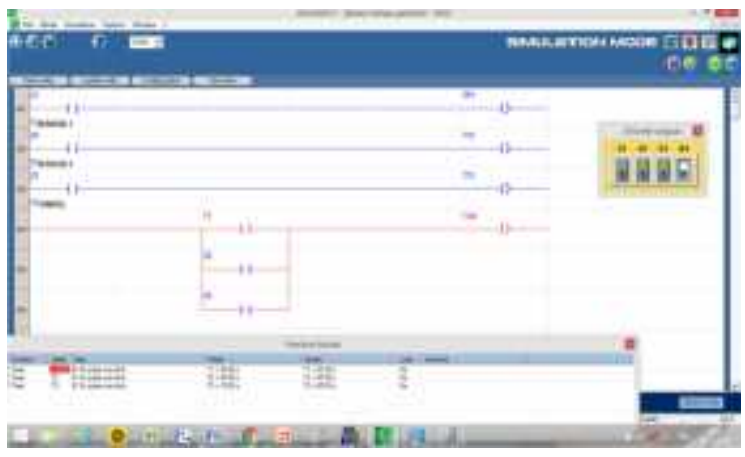

Gambar 3. Simulasi Sensor 1

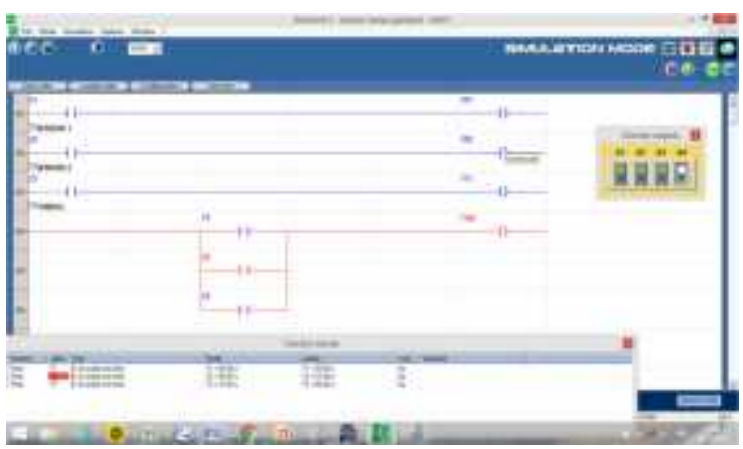

Gambar 4. Simulasi Sensor 2

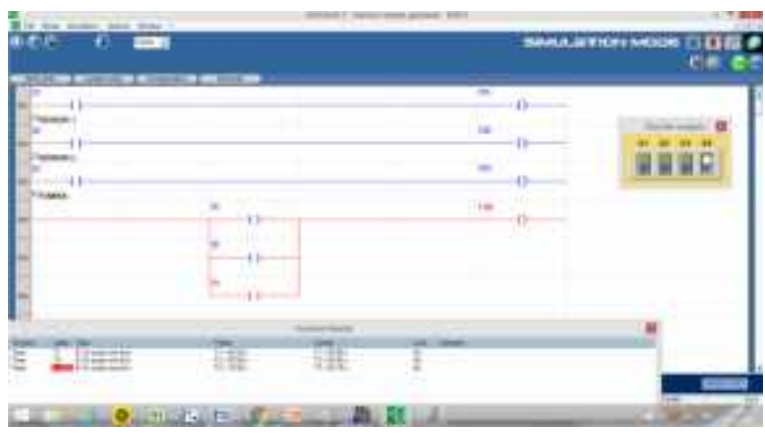

Gambar 5. Simulasi Push button 

Untuk Efisiensi Daya Listrik

\section{b) Uji Perkomponen}

Tabel 1. Pengujian Hardware

\begin{tabular}{|c|c|c|c|c|}
\hline No & Rancangan Blok & Kriteria & Hasil Analisis & Ket. \\
\hline a. & $\begin{array}{l}\text { Merancang Jalur } \\
\text { Sumber Teg. } \\
\text { a. Jalur Penerangan } \\
\text { b. Jalur Kontrol }\end{array}$ & $\begin{array}{l}\text { a. Sumber } \\
\text { Penerangan: } \\
1 \mathrm{MCB} / \mathrm{FB} \text { dan ada } \\
11 \mathrm{FB} \\
\text { b. Di bagi menjadi } \\
2 \text { group } \\
\text { c. Mencari sumber } \\
\text { Teg. terdekat untuk } \\
\text { panel kontrol }\end{array}$ & $\begin{array}{l}\text { a. Instalasi penerangan dari } \\
\text { Sub panel lama } \\
\text { b. Bag. barat \& bag. timur } \\
\text { - Sub panel } 23 \text { bag. barat } \\
\text { - Sub panel } 28 \text { bag. timur }\end{array}$ & $\begin{array}{l}\text { Ok } \\
\text { Ok }\end{array}$ \\
\hline b. & Power Supply & $\begin{array}{l}\text { a. Vin } 220 \mathrm{VAC} \\
\text { b. Vout DC } 24 \mathrm{~V} \pm . \%\end{array}$ & $\begin{array}{l}\text { a. Vin } 220 \mathrm{VAC} \\
\text { b. Vout DC } 24,6 \mathrm{~V}\end{array}$ & Ok \\
\hline c. & $\begin{array}{l}\text { PLC type } \\
\text { SR2B121BD Timer }\end{array}$ & $\begin{array}{l}\text { Timer delay off } 5 \\
\text { menit akan bekerja } \\
\text { sesaat setelah } \\
\text { mendapat tegangan } \\
\text { trigger } 24 \text { VDC. }\end{array}$ & $\begin{array}{l}\text { Keluaran smart relay tetap } \text { On } 5 \\
\text { menit setelah tegangan trigger } \\
24 \text { VDC off. }\end{array}$ & Ok \\
\hline d. & $\begin{array}{l}\text { Merancang bahasa } \\
\text { pemrograman sensor }\end{array}$ & $\begin{array}{l}\text { a. Mudah dimengerti } \\
\text { b. Hampir disemua } \\
\text { PLC ad }\end{array}$ & Ladder Diagram & Ok \\
\hline e. & $\begin{array}{l}\text { a. Sensor cahaya } \\
\text { dengan Celcon AS- } \\
\text { 220-3A } \\
\text { b. Sensor Infrared } \\
\text { BM3M - TD }\end{array}$ & $\begin{array}{l}\text { a. } 400 \text { lux off } \\
\text { b. } 80 \text { lux on } \\
\text { c. Teg. } 24 \mathrm{VDC} \\
\text { d. Jarak } 3 \text { meter } \\
\text { e. Berlogika } 1 \text { bila } \\
\text { terpotog sinar } \\
\text { Infrarednya }\end{array}$ & $\begin{array}{l}\text { a. Jam 05:30 wib off } \\
\text { b. Jam 17:30 wib on } \\
\text { c. Teg. Input } 24 \text { VDC } \\
\text { d. Jarak } 3 \text { meter } \\
\text { e. Memberikan trigger teg. } 24 \\
\text { VDC ke Smart Relay }\end{array}$ & $\begin{array}{l}\text { Ok } \\
\text { Ok }\end{array}$ \\
\hline
\end{tabular}

Jarak fixed bridge no.1 dengan no.11 kurang lebih 600 meter dan untuk memudahkan pemeliharaan atau perbaikan penerangan di area lorong fixed bridge maka pemasangan rancangan sistem kendali ini akan dibagi menjadi dua group atau kelompok dimana masing - masing kelompok terdiri dari 6 buah dan 5 buah fixed bridge.

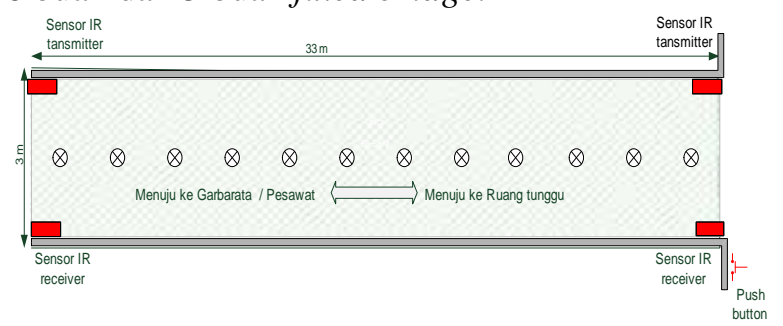

Gambar 6. Penempatan Rancangan

Photoelectric sensor ini dipasang pada pintu masuk dan pintu keluar lorong fixed bridge. Sensor dipasang dengan Jarak $\pm 40 \mathrm{~cm}$ diatas lantai. Kerja dari sensor ini apabila sinar infrared terhalang atau terpotong oleh pergerakkan penumpang yang melewati lorong fixed bridge maka sensor akan mengirim data digital (logika 1 dan 0) ke PLC. Kemudian PLC akan memproses data tersebut sesuai dengan program yang kita masukkan.

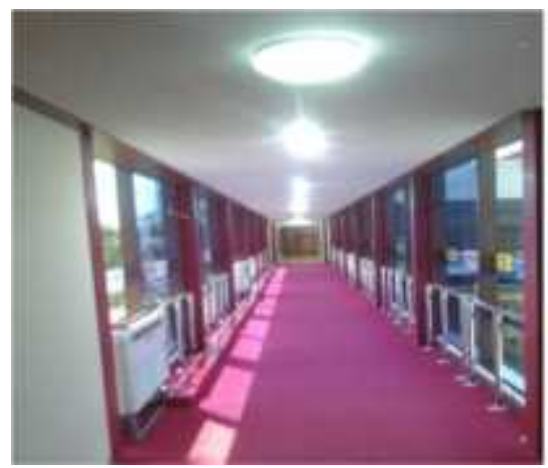

Gambar 7. Sebelum dipasang Rancangan

Dengan kuat cahaya 80 lux sensor cahaya akan $O n$ dan memberikan tegangan inputan ke rancangan, sedangkan pada kuat cahaya 400 lux sensor cahaya akan Off dan memutuskan tegangan ke rancangan. Hasil kerjanya sesuai yang diinginkan yaitu $O n$ jam 17:30 wib dan Off jam 05:30 wib. 


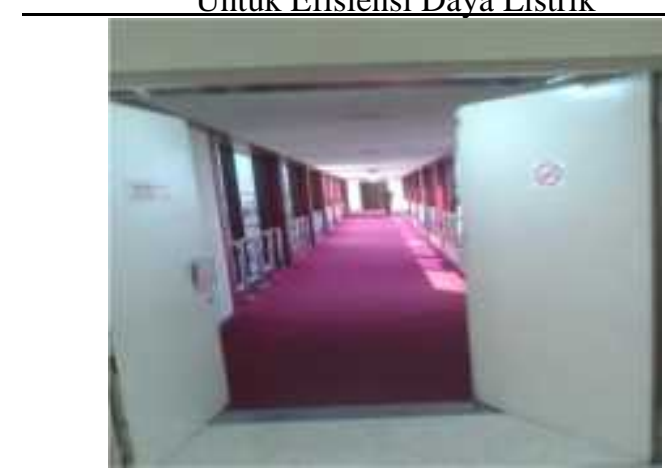

Gambar 8. Setelah dipasang rancangan

\section{KESIMPULAN}

Kesimpulan dari penelitian ini adalah

1. Power Supply Unit dengan menggunakan IC LM 7824 didapat tegangan DC murni 24V sebagai tegangan kerja Photoelectric Sensor, Smart Relay dan Relai 24VDC pada rancangan.

2. Programmable Logic Controller yang sesuai dengan kebutuhan rancangan adalah : $30 \mathrm{I} / \mathrm{O}$ (18 input dan 12 output) dan tegangan kerja serta tegangan inputnya 24VDC.

3. Memasukkan program Ladder Diagram akan didapat alur kerja rangkaian yang mudah untuk difahami, sehingga bila ada masalah pada sistem rancangan dapat segera diatasi.

4. Sensor Cahaya dan Photoelectric Sensor a. Pada Sore hari jam 17:30 s/d 05:30 wib Dengan kuat cahaya 80 lux sensor cahaya akan $O n$ dan memberikan tegangan inputan ke rancangan, sedangkan pada kuat cahaya 400 lux sensor cahaya akan Off dan memutuskan tegangan ke rancangan. Hasil kerjanya sesuai yang diinginkan yaitu $O n$ jam 17:30 wib dan Off jam 05:30 wib.

b. Sinar infrared terpotong/terhalang Dengan sinar infrared terhalang maka out put sensor akan berlogika I dan memberikan tegangan trigger ke Programmable Logic Controller melaui relai, sehingga lampu penerangan menyalah.

5. Rancangan dapat di operasikan secara manual bila terjadi kegagalan operasi pada sistem rancangan dengan menggunakan saklar tunggal yang di pasang pada setiap panel fixed bridge.

\section{Ucapan Terima Kasih}

Ucapan terima kasih yang sebesarbesarnya disampaikan kepada kepala laboratorium Teknik Elektro Universitas PGRI Adi Buana Surabaya yang telah memberikan kesempatan kepada penulis untuk melakukan penelitian di laboratorium Teknik Elektro Universitas PGRI Adi Buana Surabaya.

\section{DAFTAR PUSTAKA}

As Built Drawing Passenger Terminal Building Elektrical. 2006. Juanda International Airport.

BL. Theraja, A.K. Theraja. 2012. Electrical Technology, New Delhi , S.Chand \& Company LTD Reprint.

Daryanto. 2010. Ketrampilan Kejuruan Teknik Elektronika. SATU NUSA. Bandung.

Eugene C. Lister. 1993. Mesin Dan Rangkaian Listrik. Erlangga.

Husanto \& Thomas. 2005. Programmable Logic Control FP Sigma, ANDI Yogyakarta.

Owen Bishop. 2004. Dasar-dasar ELEKTRONIKA. Erlangga.

Suhendar. 2005. Programmable Logic Control. GRAHA ILMU.

William Bolton. 2004. Programmable Logic Controller (PLC) Sebuah Pengantar Edisi Ketiga, Jakarta : Erlangga.

Benny Kurniawan, 2012. Metode Penelitian. Jelajah Nusa Tangerang 2012

Suharsini Arikunto Prof. DR. Prosedur Penelitian Edisi Revisi. Bhineka Cipta Jakarta 2002. 